\title{
Comparison of Conventional and Automated Blood Culture Methods for The Diagnosis of Neonatal Septicemia
}

\author{
Rezwana Nusrat Chowdhury ${ }^{1}$, Nasima Akter ${ }^{2}$, Shakeel Ahmed ${ }^{3}$, Abu Hena Md. Saiful Karim Chowdhury ${ }^{2}$ \\ ${ }^{1}$ Department of Microbiology, Cox's Bazar Medical College, Cox's Bazar, Bangladesh, ${ }^{2}$ Department of Microbiology, \\ Chattogram Medical College, Chattogram, Bangladesh, ${ }^{3}$ Department of Microbiology, Bangladesh Institute of \\ Tropical \& Infectious Diseases (BITID), Foujdarhat, Chattogram, Bangladesh.
}

\begin{abstract}
Neonatal Septicemia is a serious clinical syndrome and the definitive diagnosis is based on positive blood cultures which are obtained either by conventional or automated method. Early availability of proper isolation and identification of causative bacteria facilitates the timely initiation of appropriate antibiotic therapy. Thereby the present study was conducted to identify the bacterial causes of neonatal septicemia in the fastest possible time by comparing conventional and automated blood culture methods. This cross sectional study was done during the period from January 2018 to December 2018 and included clinically suspected cases of neonatal septicemia admitted to Neonatal Intensive Care Units of Chattogram Medical College Hospital (CMCH) and Chattogram Maa-Shishu O General Hospital (CMSOGH). Out of 178 samples, automated method detected $29(16.3 \%)$ and conventional method detected $26(14.6 \%)$ blood culture positive samples. The yield of bacteria by automated method was $100 \%$ and by conventional method was $89.7 \%$. Number of bacteria isolated only by automated method were $3(10.2 \%)$. Mean time for isolation of bacteria by automated method was 26.38 hours and by conventional method was 46.34 hours. Automated method detected $47.05 \%$ of isolated bacteria in first 24 hours but none of them were detected by conventional method within first 24 hours. Among the isolated bacteria, Klebsiella spp was most common (62.0\%). Most of the isolates were resistant to Ampicillin, Cefotaxime and Ceftazidime. Analyzing the findings of the study, there was no significant difference in the rate of isolation in each time interval $(\mathrm{p}=0.157)$ of two methods but there was significant difference in the mean time of isolation of bacteria between two methods $(\mathrm{p}=0.000004)$.
\end{abstract}

\section{Introduction}

Neonatal sepsis remains the most serious problem in neonatal intensive care and results in significant morbidity and mortality ${ }^{1}$. About $20.2 \%$ of death of newborns in Bangladesh are due to sepsis ${ }^{2}$. All neonates suspected of having sepsis should have a blood sample sent for cultures $^{3}$. Blood cultures, which are "gold standard" of Blood Stream Infection, are used to detect viable pathogens in blood, have the advantage of allowing the evaluation of their antimicrobial susceptibility ${ }^{4}$. Various manual blood culture systems are enlisted among which monophasic medium is one that consists of $50-100 \mathrm{ml}$ of brain heart infusion broth/trypticase soy broth ${ }^{5}$. Advantages of manual blood culture system include cost effectiveness and usefulness in small laboratories. The three main commercially available automated blood culture systems include BacT/ALERT blood culture systems, BACTEC

Correspondence:

Dr. Rezwana Nusrat Chowdhury

Flat \# C2, House \# 13, ANZ Legend,

Road \# 01, North Khulshi, Chattogram.

Mobile: 01718-548602

E-mail: rezwananusratchy@gmail.com
9000 series and the Versa TREK system. The advantages of these systems encompass higher sensitivity for organism recovery, faster time to positivity, fully automated and computerized $^{6}$. The ideal blood culture system assembles the maximum yield of pathogen as early as possible in order to have maximum influence on patient management ${ }^{7}$. Different comparative studies including ours have reported different percentages of bacterial growth along with yield of bacteria by both methods ${ }^{8,9}$. In case of life threatening conditions like neonatal sepsis, irrational use of antibiotics have swayed the sensitivity pattern of microbes, which are evident in several recent studies thus making the use of unconventional drugs compulsory and lifesaving ${ }^{10,11}$. So, earlier detection of bacteria is of utmost importance for facilitating the accurate treatment with the required antibiotics that minimizes the use of unnecessary antibiotics. The scarcity of relevant data among our local population have strengthen the need for an amending study regarding functionalities of both conventional and automated blood culture methods along with antibiotic susceptibility patterns. 


\section{Materials And Methods}

This cross sectional study was carried out in The Department of Microbiology, Chattogram Medical College Hospital $(\mathrm{CMCH})$ and the Department of Microbiology, Chattogram Maa-O-Shishu Hospital Medical College (CMOSHMC), Chattogram from January 2018 to December 2018. A total of 178 neonates admitted to Neonatal Intensive Care Units (NICU) of $\mathrm{CMCH}$ and CMOSHMC, who had accomplished the eligibility criteria of clinically suspected cases of neonatal sepsis ${ }^{12}$ were included in the study.

\section{Methods of collection and inoculation of blood sample:}

After explaining the procedure and taking written informed consent to the patient parties, a single sample of $2 \mathrm{ml}$ of venous blood was drawn from each patient ${ }^{13,14}$. Strict skin antisepsis was performed following the established guidelines ${ }^{15,16,17}$. After removing the syringe and needle from venipuncture site, the sampling needle were discarded and replaced by fresh sterile needle. The top of the rubber stopper of both conventional and automated blood culture bottles were disinfected by $70 \%$ ethyl alcohol swab, than $1 \mathrm{ml}$ of blood were introduced in the conventional blood culture bottle containing $10 \mathrm{ml}$ trypticase soya broth and $1 \mathrm{ml}$ of blood was introduced in the automated blood culture bottle. Immediately after introduction of blood, inoculated bottles were gently shaken a few times to mix the blood in the broth medium. These procedures were performed at the bedside of patients ${ }^{18}$.

Laboratory procedure: Both manual and automated blood culture bottles were incubated at $35^{\circ} \mathrm{C}$ to $37^{\circ} \mathrm{C}$ aerobically ${ }^{18}$. For the purpose of isolation of bacteria in conventional methods, dehydrated SPS (Sodium Polyanethol Sulphonate) and TSB base were used to prepare $10 \mathrm{ml}$ of broth according to standard laboratory procedure. The inoculated bottles were periodically examined for macroscopic evidences such as turbidity, hemolysis, puffballs and gas production ${ }^{19}$. Initial blind subcultures were performed after 12-18 hours or after overnight incubation $^{17,20}$. Subcultures were done in blood agar, MacConkey agar and Chocolate agar medias as soon as macroscopic changes were observed ${ }^{18}$ and also in absence of macroscopic changes, subcultures were done at least twice during the first 2-3 days. When no growth was observed by subcultures, then a final subculture was done before discarding the bottle after 7 days of incubation ${ }^{21,22,23}$. Microscopic examination of gram stained smears prepared from colonies from subcultures were done accordingly ${ }^{17}$. After isolation mean time for total number of isolated bacteria was calculated, then mean deviation was calculated, after that Standard Deviation was calculated, using the formula $\left.\mathrm{SD}=\sqrt{\Sigma\left(\mathrm{x}^{-} \mathrm{n}^{-}\right.}\right)^{2}$. Total mean for isolation of bacteria was calculated by using the formula mean \pm SD.

Identification of isolated bacteria along with the antimicrobial susceptibility testing was performed by modified Kirby Bauer Disc Diffusion Method according to The Clinical and Laboratory Standards Institute (CLSI) guideline 2017 and Food and Drug Administration (FDA) 2013 24, 25, 26, 27.

Isolation of bacteria by automated method: BACTEC FX 40 blood culture systems were used. The pediatric version of aerobic blood culture bottles of above automated systems each containing $30 \mathrm{ml}$ of complex medium with inoculated $1 \mathrm{ml}$ of blood samples were loaded into the respective machines ${ }^{28}$ and then continuously monitored at 10-24 minutes intervals for evidences of growth. They were incubated at $37^{\circ} \mathrm{C}$ for up to 5 days when no signal was recorded ${ }^{20,29}$. Whenever the machines gave positive signal, Time To Positivity (TTP) was noted. Time To Positivity (TTP) is a parameter provided by the automated blood culture system and is calculated from the time of incubation until a positive signal is detected ${ }^{6}$. The total time of isolation by automated method was calculated by adding TTP and time taken for positive subculture. The mean time for isolation of bacteria was calculated. Total mean for isolation of bacteria was calculated using the equations used in conventional method. After that the comparison between two means (conventional and automated) method was done by unpaired t-test. Steps of laboratory procedures after signal positive bottles were taken for subcultures.

Data analysis: The results of the experiments were recorded systematically and statistical analysis was done by SPSS for Windows version 20 software. Statistical significance was defined as $\mathrm{P}<0.05$ and confidence interval was set at $95 \%$ level. $X^{2}$ (chi-square) test was done to test the significances of calculated results. Unpaired t-test was done to compare the calculated means. 


\section{Results}

Table-I: Results of positive blood culture by conventional and automated methods among study population $(n=178)$ :

\begin{tabular}{|c|c|c|}
\hline Methods & Number & Percentages \\
\hline Conventional & 26 & 14.6 \\
\hline Automated & 29 & 16.3 \\
\hline
\end{tabular}

$\mathrm{P}$-value $=0.157, \mathrm{P}>0.05$, statistically no significant difference.

Table-I shows the rate of blood culture positivity by automated and conventional blood culture methods among study population. Among the study population of $178,29(16.3 \%)$ samples were positive by automated method and $26(14.6 \%)$ were positive by conventional method.

Table-II: Comparison of yield of bacteria by conventional and automated methods $(n=29)$ :

\begin{tabular}{|c|c|c|}
\hline Methods & Number & Percentage \\
\hline Conventional & 26 & 89.7 \\
\hline Automated & 29 & 100 \\
\hline
\end{tabular}

$\mathrm{P}$-value $=0.157, \mathrm{P}>0.05$, statistically no significant difference.

Table-II shows among 29 samples with positive growth, automated method detected 29 (100\%) samples, while conventional method detected $26(89.7 \%)$ samples.

Table-III: Distribution of isolated bacteria by conventional and automated methods $(n=29)$ :

\begin{tabular}{|l|c|c|c|l|}
\hline $\begin{array}{c}\text { Name } \\
\text { of the } \\
\text { bacteria }\end{array}$ & $\begin{array}{c}\text { Number } \\
(\%) \text { of } \\
\text { bacteria } \\
\text { isolated } \\
\text { by both } \\
\text { methods }\end{array}$ & $\begin{array}{c}\text { Number } \\
(\%) \text { of } \\
\text { bacteria } \\
\text { isolated } \\
\text { by only } \\
\text { automated } \\
\text { method }\end{array}$ & $\begin{array}{c}\text { Number } \\
(\%) \text { of } \\
\text { bacteria } \\
\text { isolated } \\
\text { by only } \\
\text { conventional } \\
\text { method }\end{array}$ & Total \\
\hline Klebsiella $\mathrm{spp}$ & $18(62.0 \%)$ & 0 & 0 & $18(62.0 \%)$ \\
\hline Escherichia coli & $1(3.4 \%)$ & $1(3.4 \%)$ & 0 & $2(6.8 \%)$ \\
\hline Acinetobacter $\mathrm{spp}$ & $6(21.0 \%)$ & 0 & 0 & $6(21.0 \%)$ \\
\hline Pseudomonas $\mathrm{spp}$ & $1(3.4 \%)$ & $1(3.4 \%)$ & 0 & $2(6.8 \%)$ \\
\hline Serratia spp & 0 & $1(3.4 \%)$ & 0 & $1(3.4 \%)$ \\
\hline Total & $26(89.8 \%)$ & $3(10.2 \%)$ & 0 & $29(100 \%)$ \\
\hline
\end{tabular}

P-value of bacteria isolated by only automated method $=0.287$. $\mathrm{P}$-value of bacteria isolated by only conventional method $=\mathrm{NA}$. (P- value reached from chi-square test).

Table-III shows distribution of isolated bacteria by conventional and automated blood culture system. The highest number of bacteria isolated were Klebsiella spp $18(62.0 \%)$, followed by Acinetobacter spp 6 (21.0\%), both Pseudomonas spp and Escherichia coli each 2 $(6.8 \%)$ and Serratia spp 1 (3.4\%). Among the 29 isolated bacteria, $26(89.8 \%)$ were isolated by both conventional and automated methods and $3(10.2 \%)$ were isolated only by automated method. No bacteria was isolated only by conventional method. The bacteria isolated only by automated methods 3 (10.2\%) were Escherichia coli, Pseudomonas spp and Serratia spp.

Table-IV: Comparison of two methods depending on time taken to be blood culture positive:

\begin{tabular}{|c|c|c|c|c|c|c|}
\hline \multirow[t]{2}{*}{ Time } & \multicolumn{2}{|c|}{$\begin{array}{l}\text { Number }(\%) \text { of } \\
\text { isolated bacteria }\end{array}$} & \multirow[b]{2}{*}{ P-value } & \multicolumn{2}{|c|}{$\begin{array}{l}\text { Mean } \pm \text { SD } \\
\text { (in hours) }(n=29)\end{array}$} & \multirow[b]{2}{*}{ P-value } \\
\hline & Conventional & Automated & & Conventional & Automated & \\
\hline $\begin{array}{l}12-24 \\
\text { hours }\end{array}$ & 0 & $15(51.7)$ & 0.157 & $46.34 \pm 20.53$ & $26.4 \pm 4.67$ & 0.000004 \\
\hline $\begin{array}{l}>24-48 \\
\text { hours }\end{array}$ & $13(50.0 \%)$ & $14(48.3 \%)$ & 0.157 & \multirow[t]{3}{*}{$46.34 \pm 20.53$} & \multirow[t]{3}{*}{$26.4 \pm 4.67$} & \multirow[t]{3}{*}{0.000004} \\
\hline $\begin{array}{l}>48-72 \\
\text { hours }\end{array}$ & $13(50.0 \%)$ & $14(48.3 \%)$ & 0.157 & & & \\
\hline $\begin{array}{l}>72 \\
\text { hours- } \\
5 \text { days }\end{array}$ & 0 & 0 & 0.157 & & & \\
\hline
\end{tabular}

$\mathrm{P}$-value of rate of isolation in each time interval was 0.157 (reached through chi-square test), $\mathrm{P}>0.05$; no significant difference in the rate of isolation.

P-value of two means was 0.000004 , (reached through unpaired $\mathrm{t}$-test), $\mathrm{t}$ value $=5.100, \mathrm{P}<0.05$, so difference between two means is statistically significant.

Table-IV shows the time (in hours) interval for the isolation of bacteria. Mean time for isolation of the bacteria in automated method was $26.4 \pm 4.67$ hours, whereas in conventional method the mean time was $46.34 \pm 20.53$ hours. $15(51.7 \%)$ of the bacteria were identified within 24 hours and $14(48.3 \%)$ by $>24-48$ hours in automated method. So, up to 48 hours, total $29(100 \%)$ bacteria were isolated in automated method. In conventional method, no 
bacteria could be isolated before or at 24 hours. Equal numbers of bacteria were isolated by conventional method in $>24-48$ hours interval and $>48-72$ hours interval which was $13(50.0 \%)$.

Table-V: Rate of contamination of blood cultures by conventional and automated method $(n=178)$ :

\begin{tabular}{|c|c|c|}
\hline Methods & Number & Percentage \\
\hline Conventional & 7 & 3.9 \\
\hline Automated & 5 & 2.8 \\
\hline
\end{tabular}

$\mathrm{P}$ - value $=0.157 . \mathrm{P}>0.05$, statistically no significant difference.

Table-V shows the rate of contamination in conventional method were $7(3.9 \%)$ and automated blood culture method were 5 (2.8\%) among 178 blood samples.

Table-VI: Antimicrobial susceptibility pattern of important isolated bacteria against different antimicrobial agents:

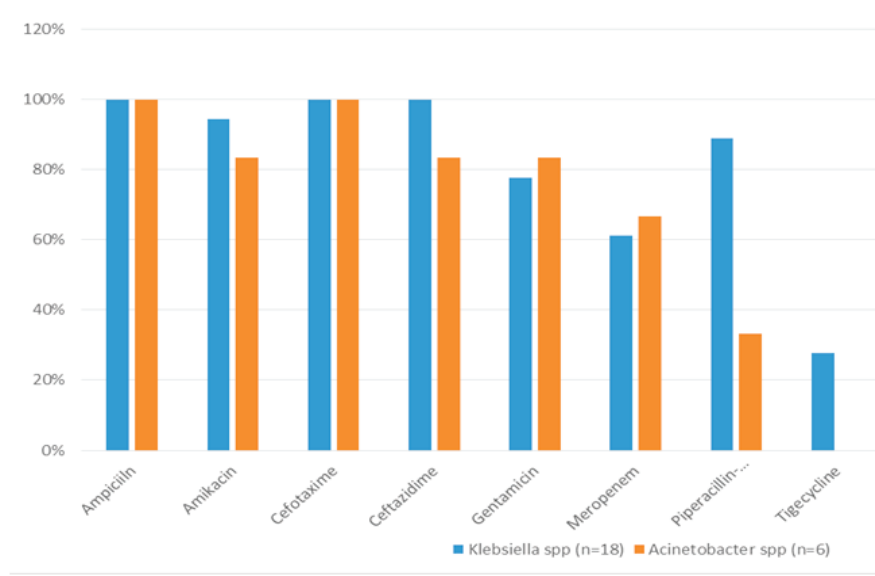

Table-VI shows the susceptibility pattern of important isolated bacteria against different antimicrobial agents. Among the 18 isolated Klebsiella spp, 18 (100\%) were resistant to Ampicillin, Cefotaxime and Ceftazidime, followed by 17 (94.4\%); resistant to Amikacin and 16 $(88.89 \%)$ to Piperacillin-tazobactum, $14(77.78 \%)$ to Gentamicin, 11 (61.1\%) to Meropenem and 5 (27.81\%) to Tigecycline. Among the 6 isolated Acinetobacter spp, 6 (100\%) were resistant to Ampicillin and Cefotaxime, followed by $5(83.4 \%)$ to Amikacin, Gentamicin and Ceftazidime each, $4(66.7 \%)$ to Meropenem and 2 $(33.3 \%)$ to Piperacillin-tazobactum.

\section{Discussion}

In our study, out of 178 blood culture samples, 29 $(16.3 \%)$ isolates were culture positive by automated method and $26(14.6 \%)$ of them were positive by conventional method. These findings are similar with a comparative study that stated $24.1 \%$ positive blood culture detected by automated method and $17.9 \%$ positive blood culture by conventional method ${ }^{30}$. The yield of bacteria by two methods was also compared in our study. It showed that yield of bacteria by automated method was 100\% (29/29) as compared to conventional method which had $89.7 \%$ (26/29) yield of bacteria. These findings are similar to a study that showed yield of bacteria by automated and conventional methods were $96.9 \%$ and $80 \%{ }^{9}$. Our study showed among the isolated bacteria, Klebsiella spp (62.0\%) was predominant, followed by Acinetobacter spp (21.0\%), Escherichia coli and Pseudomonas spp (6.8\%) each and Serratia spp (3.4\%). Another recent study had the same finding of highest number of Klebsiella spp $(30.66 \%)$ followed by Acinetobacter spp $(20.0 \%)^{10}$. The present study showed among the 29 culture positive isolates, $3(10.2 \%)$ were positive only by automated method but none was positive only by conventional method. This may be due to composition of automated vials that contain either resin or charcoal which are responsible for effective removal of antimicrobial agents from blood whereas conventional bottles do not contain these ingredients. So removal of antimicrobial agents is not possible in eonventional method. Another congruous study had the findings of $32 \%$ blood culture positive samples only by automated method but none were positive by conventional method ${ }^{31}$. The rate of isolation of bacteria in relation to time has been calculated in our study. The earliest time of isolation of bacteria by automated method was within 12-24 hours interval and the rate of isolation was $51.7 \%$ but no bacteria was isolated in 12-24 hours interval by conventional method. The similar findings of $45 \%$ isolated bacteria by automated method but none by conventional method in 12-24 hours interval was found in another study that correlated with our study ${ }^{8}$. In the present study highest rate of isolation of bacteria by conventional method was $50.0 \%$ in $>24-48$ hours. It correlates with a finding of $57.73 \%$ isolated bacteria in a comparative study ${ }^{8}$. Another study stated $34 \%$ of isolated bacteria within 48 hours by conventional method ${ }^{9}$. In our study, mean time for isolation of bacteria by conventional and automated methods were 46.34 hours and 26.38 hours which is similar to a study that showed mean time for conventional and automated methods as 51.09 hours and 
28.09 hours $^{32}$. Another study stated that mean time for conventional and automated methods were 66.95 hours and 15.83 hours $^{33}$. In the present study, bacterial isolates were tested for antimicrobial susceptibility by Modified Kirby Bauer Disc Diffusion technique according to CLSI guideline 2017 and FDA guideline 2013. Among the 18 isolated Klebsiella spp, all were resistant to Ampicillin, Cefotaxime and Ceftazidime which is similar to a relevant study ${ }^{34}$. In our study, most Klebsiella spp were sensitive to Tigecycline which is concordant to a similar study ${ }^{35}$. Another similar study showed that Klebsiella spp was mostly sensitive to Meropenem ${ }^{36}$. Among the 6 isolates of Acinetobacter spp, all of the isolates (100\%) were resistant to Ampicillin and Cefotaxime, followed by $83.4 \%$ to Amikacin, Gentamicin and Ceftazidime. Similar resistance against Ampicillin and Cefotaxime were observed in a study in Pakistan $^{34}$ and against Ceftazidime, Amikacin, and Gentamicin $85.7 \%$ each in a recent Bangladeshi study ${ }^{11}$. Our study showed that Acinetobacter spp were mostly sensitive to Piperacillin-tazobactum (66.66\%) which is similar to a recent study ${ }^{37}$.

A high level of resistance was observed against Ampicillin, Cefotaxime and Ceftazidime in our study against isolated bacteria which is very alarming. In our study, automated system of blood culture had significantly shorter meantime for isolation of bacteria than conventional blood culture system. Many of the laboratory facilities dealing with large number of samples in our country are still based on conventional blood culture system which is labor-intensive for the manpower of the laboratories and also consumes more time and thus delivery of antibiotic sensitivity reports of the patients are further delayed.

\section{Conclusion}

Conventional method of blood culture was found to be as efficient as automated blood culture method in respect to rate of isolation of bacteria and yield of bacteria though automated method had significantly shorter mean time of isolation of bacteria than conventional method. However, it is impossible to assume a complete picture of comparison between conventional and automated blood culture methods for the diagnosis of neonatal septicemia with different constraints such as limitation of time period and samples. Klebsiella spp was the commonest bacteria isolated by both methods. The isolated bacteria were resistant to most of the antimicrobial agents. So, establishment of automated blood culture system in hospitals where large numbers of patients get admitted can be an alternative to reduce the workload of microbiology laboratory. For this purpose, focusing on maintaining cost effectiveness of automated method along with the accessibility of other requirements should be accepted as areas of concerns.

\section{Disclosure}

The author reports no conflicts of interest in this work.

\section{Acknowledgements}

This study was funded partially by DGHS (Directorate General of Health Services), Bangladesh, under Issue no: DGHS/ME \& HMD/ 2018-19/ 242, dated: 25-04-2019.

\section{References}

1. Wu JH, Chen CY, Tsao PN, Hsieh WS, Chou HC. Neonatal sepsis: a 6-year analysis in a neonatal care unit in Taiwan. Pediatrics \& neonatology. 2009 Jun 1;50(3):88-95.

2. Child mortality estimates.World Health Organization and Maternal and Child Epidemiology Estimation Group; 2017[Cited 2019 Jan 23].Available from: http://data.unicef.org.

3. Simonsen KA, Anderson-Berry AL, Delair SF, Davies HD. Early-onset neonatal sepsis. Clinical microbiology reviews. 2014 Jan;27(1):21-47.

4. Mancini N, Carletti S, Ghidoli N, Cichero P, Burioni $\mathrm{R}$, Clementi M. The era of molecular and other non-culture-based methods in diagnosis of sepsis. Clinical microbiology reviews. 2010 Jan;23(1):235-51.

5. Sastry AS, Bhat KS. Clinical microbiology (infectious syndrome). In: Sastry AS, Bhat KS,Janagond A,editors. Essentials of Medical Microbiology. $1^{\text {st }}$ ed. New Delhi: Jaypee Brothers Medical Publishers (P) Ltd; 2016.p.585-605.

6. Blood Culture Systems: From Patient to Result. Sepsis-An Ongoing and Significant Challenge; 2012 [Cited2018 Dec 8]. Available from: http://dx.doi.org/10.5772/50139.

7. Public Health England (PHE) and National Health Service (NHS). UK Standards for Microbiology Investigations; 2013 [Updated $2021 \mathrm{Jul}$ 1; cited 2018 Dec 8]. Available from: https://www.gov.uk/government/collections/standards-for-microbiology-investigations-smi. 
8. Fernandes A, Boloor R, Dias M, Antony B, Pinto H, Kuruvilla TS. A comparative study of conventional and BACTEC 9120 blood culture methods. Muller Journal of medical sciences and research. 2011;2(2):8-13.

9. Rajan LL, Jayalekha B, Sreekumary PK, Harikumar S. A comparative study on conventionl and automated blood culture in the early detection of bacterial pathogens. Journal of evolution of medical and dental sciences. 2017;6(31):2502-2506.

10. Nayak S, Rai R, Kumar VK, Sanjeev H, Pai AKB, Ganesh HR. Distribution of microorganisms in neonatal sepsis and antimicrobial susceptibility patterns in a tertiary care hospital. Archives of medicine and health sciences. 2019;2(2):136-139.

11. Shirin M, Hossain MM, Afrin M, Mamun MA. Bacterial etiology and antibiotic resistance pattern of neonatal sepsis: a study in a tertiary care hospital, in Bangladesh. International journal of contemporary pediatrics. 2019;6(5):1-6.

12. Stoll BJ, Shane AL. Infections of the neonatal infant. In: Kligeman RM, Stanton BF, Schor NF, Geme JWS, Behrman RE, editors. Nelson Text Book of Pediatrics. 20 ${ }^{\text {th }}$ ed. Philadelphia: Elsevier; 2016. p.909-925.

13. Miller JM, Binicker MJ, Campbell S, Carroll KC, Chapin KC, Gilligan PH, et al. A guide to utilization of the microbiology laboratory for diagnosis of infectious diseases: 2018 update by the Infectious Diseases Society of America and the American Society for Microbiology. Clinical infectious diseases. 2018; 67(6):e1-e94.

14. Ringer SA, Grey JE. Common neonatal procedures. In: Cloherty JP, Eichenwald EL, editors. Manual of Neonatal Care. $7^{\text {th }}$ ed. Philadelphia: Lippincott Williams \& Wilkins; 2012.p.851-869.

15. WHO guidelines on drawing blood: best practices in phlebotomy, Geneva, Switzerland: World Health Organization; 2010.

16. Sepsis in the Newborn. All India Institute of Medical Sciences (AIIMS); 2008 [Cited 2019 Aug 19]. Available from: http://newbornwhocc.org/pdf/ sepsis_innewborn.pdf.
17. Cheesbrough M. Culturing blood. In: District Laboratory Practice in Tropical Countries Part 2. $2^{\text {nd }}$ ed. Cambridge: Cambridge University Press; 2006.p. 124-130.

18. Reimer LG, Wilson ML, Weinstein MP. Update on detection of bacteremia and fungemia. Clinical microbiology reviews. 1997;10(3):444-465.

19. Ombelet S, Barbe B, Affolabi D, Ronat JB, Lompo P, Lunguya $\mathrm{O}$, et al. Best practices of blood cultures in low-and middle-income countries. Frontiers in medicine. 2019;69(131):1-27.

20. Blood Cultures IV [booklet]. Washington DC: American Society for Microbiology Press; 2005.

21. Collee JG, Marr W. Culture of bacteria. In: Collee JG, Mackie TJ, McCartney JE, editors. Mackie \& McCartney Practical Medical Microbiology. $14^{\text {th }}$ ed. NewYork: Churchill Livingstone; 1996.p.113-130.

22. Murray PR. Determination of the optimum incubation period of blood culture broths for the detection of clinically significant septicemia. Journal of clinical microbiology.1985;21(4):481-485.

23. Isenberg HD, Garcia LS. Blood Cultures General Detection and Interpretation. In: Isenberg HD, Garcia LS, editors. Clinical Microbiology Procedures Handbook Vol 1. 127 th ed.Washington DC: American Society for Microbiology Press; 2007.p. 3.4.1.1-3.4.1.18.

24. Cheesbrough, M. Biochemical tests to identify bacteria.In: District Laboratory Practice in Tropical Countries Part 2. $2^{\text {nd }}$ ed. Cambridge: Cambridge University Press; 2006.p.62-70.

25. Kirby-Bauer Disk Diffusion Susceptibility Test Protocol. American Society for Microbiology; 2016 [Cited 2019 Aug 10]. Available from: https://www. asm.org/getattachment/2594ce26-bd44-47f68287-0657aa9185ad/Kirby-Bauer-Disk-Diffusion-Susceptibility-Test-Protocol-pdf.pdf.

26. Clinical and Laboratory Standards Institute. CLSI Document M02 and M07, Performance Standards for Antimicrobial Susceptibility Testing M100, 27 ${ }^{\text {nd }}$ ed. Wayne, Pennysylvania: Clinical and Laboratory Standards Institute, 2017. 
27. Tygacil (tigecycline). Food and Drug Administration; 2013. [Cited 2019 May 26]. Available from: https:// www.accessdata.fda.gov/drugsatfda_docs/label/2013/021821s026s0311bl.pdf.

28. BACTEC TM Peds Plus TM/F Culture Vials (plastic). Becton, Dickinson and Company; 2016 [Cited 2019 July 25]. Available from: http://legacy.bd.com/ds/ technical Center/inserts/500008334(02).pdf.

29. Shin KS. Overview of blood culture: key elements in CLSI guidelines and rapid detection methods. In LMCE 2017 \& KSLM 58th Annual Meeting,18-20 October 2017; Grand Walker hill Seoul, Korea: Korean Society for Laboratory Medicine;2017.

30. Bose S, Vishal G. Utility of BACTEC blood culture system versus conventional blood culture method for detection of bacteremia in pediatric patients.International Journal of Current microbiology and applied sciences. 2018;7(10):1126-1131.

31. Kaur A, Soodan PS, Singh VA. Comparative evaluation of conventional blood culture with BACTEC 9050 for bacterial isolates in clinically suspected cases of fever of unknown origin. IOSR journal of dental and medical sciences. 2018;13(7):17-21.

32. Begum MF. Comparison of newly designed modified automated faster antibiotic neutralizer aerobic blood culture with conventional blood culture system for the diagnosis of septicemia. [Thesis]. Dhaka: Bangabandhu Sheikh Mujib Medical University; 2005.
33. Elantamilan D, Wihiwot VL, Amit B, Annie K, Prithwis $\mathrm{B}$, Jyotismita $\mathrm{R}$, et al. Comparative evaluation of conventional (manual) blood culture system and BacT/ALERT 3D (automated) blood culture system in a tertiary care hospital. Scholars journal of applied medical sciences. 2017;5(2):544-549.

34. Abbasi NB, Jabeen N, Khatoon S. Neonatal sepsis; common bacterial isolates and their antimicrobial susceptibility patterns in neonatal intensive care unit, Islamabad. The professional medical journal. 2017;24(10):1455-1460.

35. Basu M. Clinical features and drug sensitivity pattern of Klebsiella pneumoniaesepsis: a descriptive study in a level 2 neonatal care unit in India. Sri Lanka journal of child health. 2017;46(3):259-261.

36. Ahmed M, Yasrab M, Khuodil A, Qamar K, Ahmed Z. Neonatal sepsis in a tertiary care hospital: bacteriological profile and its antimicrobial sensitivity. Pakistan armed forces medical journal. 2018;68(6): 1654-1658.

37. Thapa S, Sapkota LB. Changing trend of neonatal septicemia andantibiotic susceptibility pattern of isolates in Nepal. International journal of pediatrics. 2019:1-7. 